\title{
Design Thinking and Participation: Lessons Learned from Three Case Studies
}

\author{
Olivier Glassey $^{1}$, Jean-Henry Morin ${ }^{2}$, Patrick Genoud ${ }^{3}$, and Giorgio Pauletto ${ }^{3}$ \\ ${ }^{1}$ Swiss Graduate School of Public Management (IDHEAP), \\ Quartier Mouline UNIL, 1015 Lausanne, Switzerland \\ ${ }^{2}$ University of Geneva, Battelle bâtiment A, \\ Route de Drize 7, 1227 Carouge, Switzerland \\ ${ }^{3}$ Observatoire technologique et systèmes d'informations CTI, \\ Rue du Grand-Pré 64-66, 1211 Geneva, Switzerland \\ Olivier.Glassey@idheap.unil.ch, Jean-Henry.Morin@unige.ch, \\ \{Patrick.Genoud, Giorgio. Pauletto\}@etat.ge.ch
}

\begin{abstract}
This paper examines how design thinking and serious games approaches can be used to support participation through the analysis of three case studies. Indeed we will analyze these approaches in three different contexts: (i) a state-owned multi-utilities company; (ii) a political party; (iii) an information system strategic committee. Our analysis framework relies on the concepts of "perceived usefulness" and "perceived ease of use" and we will use it to discuss the lessons learned. Our main finding is that these approaches really contributing in making complex and abstract matters more "tangible" and thus understandable.
\end{abstract}

Keywords: participation; design thinking, serious games, case study, perceived usefulness.

\section{Introduction}

In this paper we will examine how design thinking and serious games approaches can be used to support participation through the analysis of three case studies. Section 1.1 addresses the issues of wicked problems, with which most public policies deal, and how innovative techniques can help solving them. Section 1.2 then presents the Think Services approach, a combination of design thinking and serious games. In section 2 we will briefly present the contexts of our three cases studies: (i) a state-owned multiutilities company; (ii) a political party; (iii) an information system strategic committee. In order to analyze these cases we will use a framework defined in section 3 and we will discuss the lessons learned in section 4.

\subsection{Tackling Wicked Problems}

According to [1] governments seek to encourage participation in order to improve the efficiency, acceptance, and legitimacy of political processes. They identify the main stakeholders of participation as citizens, non-governmental organizations, lobbyists 
and pressure groups, who want to influence the political system, as well as the opinion forming processes. Many political processes are concerned with solving wicked problems, defined by [2] as "those that defy conventional approaches to understanding, planning, design, implementation and execution because: (i) The stakeholder interests are so diverse and divisive; (ii) Interdependencies are so complex and so little understood; (iii) Behaviors are so dynamic and chaotic (unpredictable)". One approach to address wicked problem is proposed by [2]: hybrid thinking is centered amongst others on design thinking and co-creation. Similarly the VoiceS research project [3] uses serious games to support eParticipation and make "complex EU codecision procedure accessible to a large audience (especially among younger citizens), thus providing necessary understanding and enabling them to contribute actively to the platform". A game is defined by [3] "as a structured or semi-structured activity, usually undertaken for enjoyment and sometimes also used as an educational tool. Key components of games are goals, rules, challenge, and interactivity." [4] explain that the term serious game "came into wide use with the emergence of the Serious Games Initiative in 2002 (seriousgames.org)". The Serious Games Initiative website states that they are "focused on uses for games in exploring management and leadership challenges facing the public sector". [4] also believe that serious games "can be applied to a broad spectrum of application areas, e.g. military, government, educational, corporate, and healthcare."

\subsection{The Think Services Approach}

The approach used by Think Services is adapted from techniques originating from $d e$ sign thinking (for an introduction see [5, 6]) and for more on design science [7]); from the Innovation Games of Luke Hohmann [8]; and from participatory focus groups. One of the objectives of Think Services is rely on a positive lens. According to [9], this concepts "refers to a perspective in the social sciences that emphasizes the capacity of people, teams, and organizations to construct enriching work environments, create more fulfilling customer experiences and design better socio-technical systems (...)". [9] also explain that design encompasses three organizational practices: (i) actually producing artifacts; (ii) using them; and (iii) communicating about them.

In a world where management and governance processes are focused on decisionmaking, [9] strongly advises that decision-makers engage in design thinking practices. Indeed it has been assumed since the theory of innovation of Schumpeter in the 1930's that "the most important designs for innovations would originate from producers", even if individuals or other firms also contribute to innovation [10]. Here we allow ourselves to draw a parallel with policy-making and political decision-making: we have a feeling that it is also assumed that innovations come from those who are in charge. However information and communication technology and new models such as open source software and co-creation have been changing this paradigm and leading to what has been coined open innovation [10]. This is why the Think Services approach aims at co-designing policies and services. It furthermore has the goal of going beyond technological applications and making the results of multidisciplinary approaches tangible. Indeed prototypes of service innovation should be tangible [6], however tangible does not (necessarily) mean physical. The Think Services approach relies heavily on tangible outputs such as pictures, videos, shared documents and 
working spaces, and contextual mapping and presentation tools such as Prezi [11]. However it also goes further in using the leverage of tangibilization: innovation games such as Design the Service Box actually do produce a cardboard box describing the designed service. We indeed believe that in order to tackle wicked problems, tangible prototypes should be used.

Several countries and governments are currently exploring a design thinking approach similar to the one fostered through Think Services, see e.g. [12] or [13]. More generally Service Design is itself becoming a more and more developed and structured discipline that addresses a growing demand from the private and public sector see [14], [15] and [16].

\subsection{Workshops}

To support our tangible service design approach we assembled a toolbox of different workshops. The goal is twofold: first, it allows the elicitation of needs, i.e. exploring the feasibility and the viability of the ideas, and second, it builds energy and momentum with the stakeholders taking part in the workshops.

The toolbox is an evolving set. It uses several practical and academic sources to populate and help finding the right approach for the problem at hand. We do reference the work of the original authors, if they are identified, and encourage the reuse of our own resource. As of this day, several workshops are identified, not all of them are completely developed or tested. Each of them is described in a synthetic document, explaining why it is useful, how to carry it out and what the expected outputs are. The main elements described formally are the objective, the brief, the content, the output and the follow-up of the workshop. To give a brief gist of the current content of the toolbox, this is the list of the titles of selected workshops: "Hunt the stereotypes", "Shape the future trends", "Remember the future", "Create the service box", "Build the business model", "Brainstorming", "Play the service".

Let us explain in briefly two of them that we will describe in more details later in our applied case studies. In "Remember the future", we ask the participants to imagine they live in a distant future. Several scenarios are developed and assigned to different groups (these scenarios are usually taken from the outputs of "Shape the future trends"). The groups are then asked to describe the service and its environment as they would have seen it from that point of view. This forces to observe the future from a more distant future, therefore allowing to literally "Remember the future". The service is then described as if it had already been implemented.

Why is it important? It often is difficult to imagine concretely what the future service should look like. Several studies in cognitive psychology show that by examining the future we lack a frame of reference and get easily lost in the possible paths opening up. By reversing the point of view, the description of tangible elements is clearer, richer and more concrete. It is also easier to describe what steps were taken to reach the desired service. By selecting several scenarios, we allow to test the robustness of the service. This usually uncovers the similarities of the service in radically different settings. On the other hand, by looking at the contrasts, it also underlines peculiarities that might be essential success factors in given situations.

In "Create the service box", the participants are invited to physically design a box that virtually contains the desired imagined service in order to communicate its 
characteristics. This not only allows the expression of the tangible benefits and perception of the imagined service, but also lets the groups share more clearly the ideas they have about the service. These ideas will otherwise most of the time remain vague, intangible and difficult to get across. In this workshop, a service is already roughly imagined (this might be the output of a "Brainstorming" workshop combined with a "Remember the future" workshop). The process of "Create the service box" is simple. Give the participants a cardboard box, drawing material, magazines where to cut up pictures, and ask them to literally design the box to sell the service. After building the physical box, we invite them to present the result to the group and strongly encourage a narrative storytelling form. This structures the output, engages the audience and makes it easier to depict a concrete use. The short presentation of the groups is followed by a general discussion and a synthesis.

Why is the workshop useful? It mainly allows describing very vividly the service. By building a physical artifact, people usually come to a point where they stop talking and start doing. In several cases, choosing images, drawing on the box, or developing a story allow to more clearly exchange the ideas than only relying on words, without limiting them in their imagination.

Let us now explain more precisely the experiments we conducted and extract some lessons learned.

\section{Case Studies}

In this section we describe the design workshops and the three organisations in which they were organised: one state-owned multi-utilities company; one political party; the information system strategic committee of the Canton of Geneva. We will also detail the objectives of these workshops.

\subsection{Services Industriels de Genève}

The chief information officer (CIO) of the Services Industriels de Genève (SIG, the state-owned, multi-utilities company of Geneva) is in charge of a team of 10 managers responsible for the different information technology (IT) services.

The creative workshop was organized with this team about the future of the IT in the organization [17]. It was based on the Remember the future approach [18]. The main goal of the CIO was to make his colleagues stand back about the evolution of their job and of their professional environment over the next 10 to 15 years.

During the first part of the workshop the participants were asked to imagine their workplace in the year 2040 and draw it onto a board. Rather than claiming to correctly describe the reality of 2040, this initial step allowed them to immerse in this far future in a very natural way, making their thoughts tangible through the drawings. It constituted a very good starting point for the rest of the workshop with people envisioning colleagues collaborating from the other side of the planet, convergence of private and professional environments, teleworking using rich interfaces, holographic avatars, ubiquitous sensors, or pervasive virtualization.

Once "projected" in 2040, everybody had to imagine himself as the CIO of SIG celebrating his/her retirement. At this occasion the CIO is asked to tell the story of the 
building of his new team 20 years ago (in 2020) and outline why and how this team contributed to the success of the organization in the following years. Two groups were formed and asked to elaborate their scenario in different contexts. One group was supposed to imagine the evolution of the IT team in a context of commoditization: the IT and the information systems were in this case a support to the evolution of SIG. The other group worked on a contrasted scenario where the information systems were supposed to be part of the core business of SIG.

To support their thoughts each group was suggested to elaborate on IT missions of the SIG in the proposed context, on the evolution of the competencies needed to achieve these missions and on the services proposed by their teams.

Even if constructed in two very different contexts, the story proposed by each groups conveyed some common preoccupations. First, data and information was envisioned in each context as a strategic resource for the organization. The workshop helped the team to explicit the value of the information as a primary source of knowledge. Many services were imagined based upon data, information and knowledge, with new activities and competencies (such as "service trader" or "semantician") needed to deal with that.

The CIO of SIG had no peculiar expectations with respect to the outcome of the workshop. But the ideas and reflections generated during the workshop evoked different useful perspectives regarding the evolution of his organization. He mentioned as an intangible result the fact that his team stepped back with respect to their daily activities and a reinforcement of the team spirit.

Table 1. Workshop "Services Industriels de Genève"

\begin{tabular}{ll}
\hline Toolbox & Remember The Future \\
\hline Objectives & $\begin{array}{l}\text { Stand back about the evolution of the work of the } \\
\text { IT team over the next } 10 \text { to } 15 \text { years } \\
\text { Participants are asked to imagine their workplace } \\
\text { in the year } 2040 \text { and the profile of workers }\end{array}$ \\
Outputs & $\begin{array}{l}\text { New strategic data and information services; new } \\
\text { activities and competencies, such as "service } \\
\text { trader" or "semantician" }\end{array}$ \\
\hline
\end{tabular}

\subsection{Parti Démocrate Chrétien}

The Christian Democratic People's Party (Parti Démocrate-Chrétien - PDC) is a center-right wing Swiss political party. Its Geneva section invited ThinkServices to run a creative workshop for the Economic Commission on the theme of Jobs and Skills of the Future. Such a prospective issue naturally triggered their interest for co-creativity, design thinking, serious gaming thus leading to their request to experience such methods at first hand.

The roughly 2 hours Skill Box workshop was a mix of two techniques: Persona creation and Service Box. First, the participants were asked to describe the profile (persona) of the future worker. In order to be as open as possible, they were given the following categories of work to address in groups: nursing \& health care provider, teacher, bank employee, librarian, blue-collar worker or one of their personal 
choosing. They were also given a set of thinking cues in terms of: education and training (initial and lifelong), work load, places, schedules, wages, retirement, tools, recruiting, personal vs. professional life balancing, etc.

Following the persona definition the participants were asked to design the "skill box" (i.e. service box corresponding to that profile) as an actual artifact they could display in a job fair.

Finally, the groups were asked to present two things: first, the persona they imagined followed by the box they co-designed as if they had been in a "skill store". We deliberately looked at the result from the standpoint of observers. This allowed us to witness the following thought process. The participants clearly had in mind the societal drivers and requirements in terms of preparedness level of a political party. Therefore one could easily imagine that their next step could be to conduct a SWOT analysis of some of the salient aspects revealed.

Among these aspects three clearly emerged from the stories. First and foremost was the importance of technology as enabler in the areas of learning, organization and planning of work. The second aspect touched upon the growing changes in social structures and the corresponding work environment thereof. Of particular attention were the increase of working women and the redistribution of traditional family structure. Finally, the fundamental role of the networked life (i.e., social networking, virtual teams, lifelong learning, etc.) in all aspects of both private and professional lives especially considering their blurring boundaries.

Table 2. Workshop "Parti Démocrate Chrétien"

\begin{tabular}{ll}
\hline Toolbox & Skill Box \\
\hline Objectives & $\begin{array}{l}\text { Imagine jobs and skills of the future } \\
\text { Brief }\end{array}$ \\
& $\begin{array}{l}\text { Participants are asked sketch the persona of a } \\
\text { future worker and to design the skill box corre- } \\
\text { sponding to that profile as a job announcement to } \\
\text { be shelved in a JobStore. }\end{array}$ \\
Technology as enabler for learning, organizing \\
and planning of work; growing changes in social \\
structures; fundamental role of networked life.
\end{tabular}

\subsection{Collège Spécialisé des Systèmes d'Information}

The Collège Spécialisé des Systèmes d'Information (CSSI) of the State of Geneva is constituted of 12 managers in charge of information systems of each of the State of Geneva departments. During the year 2009, the members of the CSSI wrote their strategic plan for the years 2009 to 2013 [19]. This document describes the main axes considered to give coherence to the evolution of the different information systems of the State of Geneva. It also presents the key success factors and the strategy adopted to achieve this.

The writing of this strategic plan by a working group of the CSSI allowed to quickly finalise the output. A regular sharing of the reflections with all the members of the committee ensured that everybody related to the content of the document. But the short deadline was not necessarily favourable to an effective ownership of the 
final document, at least when considering the values it was meant to convey. Yet this phase of ownership is essential if one expects a coherent and effective communication and implementation of the strategy.

So although the document has been drafted in a rather open and co-creative way, the question remained whether every member of the CSSI had really taken the ownership and appropriated the real sense of the proposed strategy. To test this and/or to make the appropriation process easier, we organized a workshop [20] bringing them together around the Create the Service Box [21] creative method.

The workshop was conducted during two hours. The participants were divided into 3 groups. In a co-creation process, each group had 45 minutes to materialize on each of the 6 faces of the box the expected benefits of the service virtually dropped off in the box: namely the strategic plan of the information systems of the State of Geneva. With managers used to mainly talk about "costs" and "quality", we emphasized the importance to also consider other values that their strategic plan can convey, namely its "value of use" and "perception".

The box allows the participants to easily pass from concepts to something more concrete, which helps them to start up again, enriching it with new ideas made tangible through pictures, drawings, carvings, mobiles or any other media supporting their imagination. The six faces of the box also make up a constraint that forces participants to get to the main points and prioritize their messages.

During the creative phase, each group tries to make the key aspects of the strategic plan tangible on the cardboard box by enriching their creative contributions. Participants exchange their standpoint and confront their visions, by using drawings, cut-out or glue.

Once the box is complete, it serves to support the narrative, the storytelling. The group tells its story and "sells" the strategic plan to different possible stakeholders (deputies, business managers, executives) with the help of the box and the symbolism it conveys. This co-construction improves the understanding and the ownership of a service that otherwise remains purely intangible. It also helps to focus on the elements of value rather than only on the expected features.

The exercise was originally intended to facilitate the ownership of the strategic plan of the CSSI by its members. But he eventually demonstrated that this appropriation was already effective: even if the narratives offered by the three groups were different, all agreed on the consistency of the messages heard. The exercise had the merit of revealing that the strategic plan has been understood and internalized by members of the committee. This finding was in itself a remarkable result of the workshop.

All participants recognized the richness of this creative method which helped passing from abstract concepts and common values to various concrete messages. Participants appreciated the fact that this method revealed their strategic plan in the form of various metaphors which, despite their lack of precision, certainly facilitate its communication to different audiences. The Create the Service Box method is then an excellent tool to master the complexity and helps to convey simpler and more accessible messages.

Finally everyone recognized the team building dimension of such a co-creative workshop led in a playful spirit. 
Table 3. Workshop “Collège Spécialisé des Systèmes d'Information”

\begin{tabular}{ll}
\hline Toolbox & Create the Service Box \\
\hline Objectives & $\begin{array}{l}\text { Appropriation of a strategic plan by the members } \\
\text { of the IT strategy board }\end{array}$ \\
Participants are asked to materialize the expected \\
benefits of the strategic plan of the information \\
systems of the State of Geneva on each of the 6 \\
faces of a box \\
Different but consistent narratives of the strategy; \\
effectiveness of the symbolism of the box to \\
convey abstract and complex messages; team- \\
building.
\end{tabular}

\section{Analysis Framework}

Our analysis framework was built ex post in order to analyze the Think Services approach. As the workshops had been documented through blog posts, pictures, video recordings, etc. it was possible to apply it in a rather coherent way. However we have to mention that no research design was developed before the series of workshops began, and that our analysis has its limitations. Still we believe that interesting lessons can be learned from these selected case studies.

In order to discuss how workshop participants perceived the Think Services approach we focus on the creation of value they support, as well as participants' satisfaction. [22] states that the value creation of a service is most of the time only looked at in terms of cost and quality, possibly of utility, but rarely in terms of perception. This is precisely what we want to look into, rather than investigating the quality or the utility of a tangible workshop's output such as a service box. We will not do a literature review here but we will use [23] as a starting point. They propose "an integrated research model that distinguishes beliefs and attitudes about the system from beliefs and attitudes about using the system". To survey the behaviour of using technology [23] rely on the well-known technology acceptance model (TAM) developed by [24]. This theory suggests that users confronted to a new technology are influenced in their use by the:

- Perceived usefulness: Davis defines it as "the degree to which a person believes that using a particular system would enhance his or her job performance";

- Perceived ease-of-use: Davis describes this as "the degree to which a person believes that using a particular system would be free from effort".

Although this theory was developed for technological systems we believe it can be applied to serious games and design thinking workshop as well. Other dimensions such as perceived risks, costs, immediacy, or fun, are not formally integrated in our assessment but will be discussed in an ad-hoc manner in the next section. 


\section{Lessons Learned}

We used the above framework as a guideline for assessing the result of this work in terms of the impact of design thinking and serious gaming as significant factors augmenting participation. These findings, although not formally surveyed are however the result of informal debriefing sessions that took place systematically after each workshop. These sessions involved gathering feedback form the participants through discussions; later discussions also took place among the workshop organizers. It is for this reason this paper is presented as "lessons learned" rather than actual formal findings. Future work to validate our hypothesis will require the use of formal quantitative and / or qualitative survey techniques.

Perceived usefulness. Based on informal discussions and debriefing sessions following all workshops, it is clear that the vast majority of workshop participants explicitly stated that both the actual outcome of the workshop and the methods used would significantly contribute to enhancing their performance in their work. Some workshops have actually led to follow up workshops or concrete actions based on the outcome.

Perceived ease-of-use. Again, all feedbacks converged acknowledging the high degree of reusability of the methods and techniques. This is further strengthened by the fact that all our workshops are documented in open workshop briefs available for anyone to take, use and enhance. The briefs describe in detail everything that is needed to run the workshops. As an example, the Create the Service Box brief can be found here [21]. One participant mentioned after a workshop that he would use these techniques in work related problem-solving and mediation meetings. This illustrates the high degree of ease of use of the approach.

Cognitive shielding and safe house phenomenon. Interestingly we have found from our participants that as an external not for profit Think Tank we carry a tremendous potential as a "safe place" for experiencing, testing, trying new ideas that would have never surfaced otherwise or would have been difficult to argue in their respective professional environments. We refer to this phenomenon as "cognitive shielding" as it basically offers a protected environment for expressing such ideas and positions with much less risk.

Power of tangibilizing the intangible. All our workshops have a strong focus on tangibilization. Whether a Service Box, Stories, etc., they all rely on the production of an artifact. The key point here is that the artifact serves as the focus point allowing a much needed intermediation between people. The attention is therefore transferred on this artifact rather than between people. Moreover, it significantly contributes to reducing the complexity of the issues being discussed. Such tangible artifacts become easier to deal with than concepts. This has also proven to be a major value of the approach. The serious gaming approach has a very strong impact on engagement. Participants feel compelled to play in teams thus contributing to team-building addressing together a common challenge. The story telling aspect also contributes to tangibilization through its metaphorical side and the fact that people become part of their stories. They therefore collectively endorse the issues they work on, are able to 
take some distance and find there is value in the process. This was particularly true for public administrations. The key lesson is definitely the power of tangibilization.

In very rare occasions we have witnessed negative reactions to the approach. The only one we are able to report on was a case where a participant following the workshop commented with a statement: "ok, that was interesting but now we need to get back to work".

Among some of the other aspects let us briefly mention the following. The perceived risks appears to be relatively low as participants are immediately put in a "safety" position through a brief introduction stressing the value of creativity, trial and error, collaboration and having fun. In terms of costs, the highest cost incurred is most likely the actual time spent for the workshop, and therefore not working as usual. From the point of view of immediacy, there is no doubt participants have instant takeaways to inspire their work. Finally having fun along the way is a key building block and success factor of the approach leveraging the creative capabilities we have.

Finally, we also learned a few useful things we share as tips and noteworthy moments to lookout for when running the workshops. Success of such techniques is greatly improved when participants are put in the proper mindset. This requires setting the context through well-known techniques like using a short video, playing a game, etc. For example, we have used the "Did you know?" video [25], a simple "yes - no" exercise among two people. Person A states ideas and person B systematically responds No arguing why it's a bad idea. Then they switch roles and person A systematically answers positively enhancing the idea of person B. Another technique is the sound ball where people exchange a virtual ball making a sound. Each person then repeats the set of sounds adding his own at the end.

Another interesting and noteworthy event is when during the workshop you see all the participants in a group get up. We have systematically witnessed this event as being the tipping point moment of success for a group. Often this is unconsciously contagious as all groups end up standing working together.

A last key element is trying to meet the deadline: indeed a good timing of the workshop is a key success factor, as well as having a dedicated timekeeper has proven to be valuable. Using observers from the organizing team can also be useful to capture noteworthy events and / or help answering questions when needed.

\section{Conclusion and Future Work}

Our experience running co-creation workshops based on design thinking and gaming in intellectually protected settings such as an independent, not for profit Think Tank has led us to witness the value of the approach for participants. This has in turn led us to discuss and consider the role played by design thinking and gaming in stimulating participation. Based on three cases we discussed the lessons learned in terms of perception of usefulness and ease of use. Stimulating and augmenting participation is a source of empowerment for people when addressing and trying to solve wicked problems. Future work involves assessing our hypothesis through formal methodologies. In doing so, we plan to study and define the criteria allowing to not only assess the workshops but also serve as best practice supporting engagement and participation based on design thinking, serious gaming, story telling and tangibilization. 
We nevertheless think this contribution already serves as background work for further studies in this area as well as report on field experience that may be helpful to practitioners in services innovation and design.

Finally another aspect we have not addressed in this paper is the organization and structure of the different workshops as a multi-entry point process. These workshops were very briefly mentioned in section 1.3 . We plan to further study this issue as we continue to develop and run the workshops.

\section{References}

1. Sanford, C., Rose, J.: Characterizing eParticipation. International Journal of Information Management 27, 406-421 (2007)

2. Newman, D., Gall, N.: Gain a Foundation in Design Thinking to Apply Gartner's Hybrid Thinking Research. Gartner Analysis (2010)

3. Holzner, M., Schepers, J., Scherer, S., Karamagioli, E.: Beyond Web 2.0 - What Serious Games, Semantics and Social Networks can Contribute to eParticipation. In: Cunningham, P.C., Miriam (eds.) Proceedings of the eChallenges e2009 Conference, pp. 1-8 (2009)

4. Susi, T., Johannesson, M., Backlund, P.: Serious Games - An Overview. Technical Report School of Humanities and Informatics University of Skövde, Sweden (2007)

5. Brown, B.T., Wyatt, J.: Design Thinking for Social Innovation. Stanford Social Innovation Review (2010)

6. Brown, T.: Design thinking. Harvard Business Review 86, 84-92, 141 (2008)

7. Vaishnavi, V.K., Kuechler, W.J.: Design Science Research Methods and Patterns: Innovating Information and Communication Technology. Auerbach Publications, Boston (2007)

8. Hohmann, L.: Innovation Games: Creating Breakthrough Products Through Collaborative Play. Addison-Wesley Professional, Reading (2006)

9. Avital, M., Boland, R.J., Lyytinen, K.: Introduction to designing information and organizations with a positive lens. Information and Organization 19, 153-161 (2009)

10. Baldwin, C., Hippel, E.V.: Modeling a Paradigm Shift : From Producer Innovation to User and Open Collaborative Innovation Modeling a Paradigm Shift : From Producer Innovation to User and Open Collaborative Innovation 1. Introduction and Overview. Innovation 1-37 (2010)

11. http://www.prezi.com/

12. Parker, S., Heapy, J.: The Journey to the Interface. How Public Service Design Can Connect Users to Reform. Demos, London (2006)

13. Thomas, E.: Innovation by Design in Public Services. Design Council, UK (2008)

14. Stickdorn, M., Schneider, J.: This is Service Design Thinking. Basics - Tools - Cases. BIS Publishers, Amsterdam (2010)

15. Kimbell, L., Seidel, V.P.: Designing for Services - Multidisciplinary Perspectives. In: Proceedings from the Exploratory Project on Designing for Services in Science and Technology-based Enterprises. Saïd Business School, University of Oxford, Oxford (2008)

16. Moritz, S.: Service Design. In: Practical Access to an Evolving Field. Köln International School of Design, London (2005)

17. Genoud, P.: Atelier "Remember the future" à SIG (2009), http://ot.geneve.ch/ot/article.php3?id_article=141

18. Morin, J.-H., Genoud, P., Pauletto, G.: Remember The Future (2009), http://bit.1y/hwmzGO 
19. Collège Spécialisé des Systèmes d'information. Plan stratégique des systèmes d'Information de l'Etat de Genève 2009-2013 (2009),

http: / / ot.geneve.ch/ot/article.php3?id_article=128

20. Genoud, P., Pauletto, G.: Atelier d'appropriation du plan stratégique des systèmes d'information (2010),

http: / / ot.geneve.ch/ot/article.php3?id_article=129

21. Pauletto, G.: Create the Service Box (2009), http: / / bit. ly/h7B3 IY

22. Ho, D.: Exploring Service Science in our current socio-economic environment. Keynote Speech IESS1.0, University of Geneva (February 17-19, 2010),

http: //www.slideshare.net/Servicesscience/diem-hoexploring-services

23. Wixon, B.H., Todd, P.A.: A Theoretical Integration of User Satisfaction and Technology Acceptance. Information Systems Research 16, 85-102 (2005)

24. Davis, F.D.: Perceived usefulness, perceived ease of use, and user acceptance of information technology. MIS Quarterly 13, 319-340 (1989)

25. http://www.youtube. com/watch?v=cL9Wu2kWwSY 